\title{
Low-Flow Polysulfone Hemodialysis Alters Lipoprotein Parameters, Paraoxonase Activity and in Vitro Incorporation of Phospholipids
}

\author{
Franciane S. Marques ${ }^{1,2}$, Alysson Luiz M. Da Silva ${ }^{3}$, Ricardo J. C. Mattoso4, Roque Aras ${ }^{4}$, \\ Rogério Jorge B. De Oliveira ${ }^{1,5}$, Júlio Cézar De Abreu Santos ${ }^{3}$, Fabio D. Couto ${ }^{3,6}$, \\ Ricardo D. Couto ${ }^{1,3}$
}

${ }^{1}$ PGBSMI/Gonçalo Moniz Research Center (CPqGM), FIOCRUZ Foundation Center, Salvador, Brazil ${ }^{2}$ Department of Biofunction, Health Institute of Science, Federal University of Bahia/UFBA, Salvador, Brazil ${ }^{3}$ Clinical Biochemistry Laboratory, Department of Clinical and Toxicological Analysis, Faculty of Pharmacy, Federal University of Bahia/UFBA, Salvador, Brazil

${ }^{4}$ Ana Neri Hospital, SESAB and Federal University of Bahia/UFBA, Salvador, Brazil

${ }^{5}$ Naval Hospital of Salvador, Brazilian Marine Forces, Salvador, Brazil

${ }^{6}$ Laboratory of Molecular Biology and Genetics at Center of Agricultural, Environmental and Biological Sciences (CCAAB-UFRB), Cruz das Almas, Brazil

Email: rdc@ufba.br

\begin{abstract}
How to cite this paper: Marques, F.S., Da Silva, A.L.M., Mattoso, R.J.C., Aras, R., De Oliveira, R.J.B., De Abreu Santos, J.C., Couto, F.D. and Couto, R.D. (2017) Low-Flow Polysulfone Hemodialysis Alters Lipoprotein Parameters, Paraoxonase Activity and in Vitro Incorporation of Phospholipids. Journal of Biophysical Chemistry, 8, 23-38. https://doi.org/10.4236/jbpc.2017.83003
\end{abstract}

Received: July 20, 2017

Accepted: August 27, 2017

Published: August 30, 2017

Copyright ( 92017 by authors and Scientific Research Publishing Inc. This work is licensed under the Creative Commons Attribution International License (CC BY 4.0).

http://creativecommons.org/licenses/by/4.0/ (c) (i) Open Access

\begin{abstract}
End stage-renal-disease (ESRD) is associated with dyslipidemia and premature atherosclerosis. The study evaluates the effect of hemodialysis (HD) on HDL-remodeling between pre- and post-HD. Was conducted a cross-sectional study with 50 ESRD male patients, undergoing HD at Ana Neri Hospital, Salvador, Brazil. All individuals were on HD for at least 3 months, into a three sessions protocol for 3 - 4 hours per week, with a polysulfone low-flow basicdialyzing-membrane and unfractionated-heparin. HDL Phospholipid-incorporation was measured by ${ }^{14} \mathrm{C}$-PL-scintillation-counting, expressed as $\%{ }^{14} \mathrm{C}$ $\mathrm{PL} / \mathrm{mL} /$ hour. Paraoxonase (PON-1) activity was measured by spectrophotometry using paraoxon as substrate. Cardiovascular risk ratios and atherogenic index of plasma were calculated. Total cholesterol, HDL-C and non-HDL-C increased at post-HD on all age groups, but without triglycerides (TG) changes. TG/HDL-C decreased in $30-39$ and $40-49$ year $(\mathrm{y})$ at post-HD ( $\mathrm{p}<$ 0.05). LDL-C/apoB increased in $>60 \mathrm{y}$, after HD ( $<<0.05)$. HDL-C/apo- AI increased in $40-49$ y $(\mathrm{p}<0.05)$ and $>60(\mathrm{p}<0.01)$. On the other hand, nonHDL-C/HDL-C reduced in $40-49$ and $>60 \mathrm{y}$, at post-HD $(\mathrm{p}<0.05)$. The linear-correlation between $\%{ }^{14} \mathrm{C}$-PL-incorporation and non-HDL-C/HDL-C was negative in $30-39 \mathrm{y}$, both at pre- $\mathrm{HD}(\mathrm{r}=-0.90 ; \mathrm{p}=0.002)$ and post-HD $(\mathrm{r}=-0.78 ; \mathrm{p}=0.022)$. Linear-correlation between PON-1 and $\%{ }^{14} \mathrm{C}-\mathrm{PL}$ -
\end{abstract}


incorporation was positive in $>60 \mathrm{y}$, both at pre- $(\mathrm{r}=0.63 ; \mathrm{p}=0.029)$ and post-HD $(\mathrm{r}=0.65 ; \mathrm{p}=0.022)$. PON-1 activity increased at pre- $(59 \pm 30)$ and post-HD $(73 \pm 38)$ in $50-59$ y $(\mathrm{p}<0.05)$. The $\%{ }^{14} \mathrm{C}$-PL-incorporation was reduced in $>60 \mathrm{y}(\mathrm{p}<0.05)$, when compared to pre- and post-HD. ESRD patients undergoing HD shows important changes on lipid-profile, PON-1-activity, cardiac risk ratios and HDL-remodeling. These results demonstrate the influence of HD with a polysulfone low-flow basic-dialyzing-membrane and unfractionated-heparin on lipoprotein metabolism.

\section{Keywords}

Hemodialysis, Dyslipidemia, Cardiovascular Risk Bioindices, PLTP, PON-1, HDL-Remodeling, Low-Flow Polysulfone Dialyzing-Membrane

\section{Introduction}

Cardiovascular disease is the major cause of death in end stage renal disease (ESRD) patients, undergoing renal replacement therapy, such as hemodialysis (HD) [1] [2]. These individuals show various metabolic abnormalities that contribute to the development of advanced atherosclerosis [3]. Besides traditional atherogenic risk factors, few biomarkers have been postulated to be relevant cardiovascular risk markers in ESRD, including aspects of malnutrition, anemia, hypoalbuminemia, elevated fibrinogen levels, oxidative stress and inflammation [4].

Uremic dyslipidemia is a common complication in patients with chronic kidney disease, which may persist or worsen during renal replacement therapy [5]. Especially in HD, lipid metabolism disturbances are characterized by reduced levels of HDL-C, apolipoprotein AI (apo-AI) and hypertriglyceridemia [6]. Some studies have shown that the dialysis method used may alter lipid profile, for example, the type of dialyzer membrane (cellulose-triacetate or polysulfone) [7] and the type of dialyzer buffer (bicarbonate-based or acetate) [8] [9].

High density lipoprotein (HDL) acts in reverse cholesterol transport, but to perform its atheroprotective functions, HDL needs to maintain stability (structure and composition). There are some key enzymes that participate in HDL and triglyceride-rich lipoproteins metabolism, such as cholesterol esters transfer protein (CETP) and phospholipid transfer protein (PLTP) [10]. The role of PL-TP in HDL remodeling is influenced by particle protein composition and triglycerides concentration [11]. Some experimental trials have demonstrated the PLTP pro-atherogenic role [12] [13], and in humans PLTP is associated with cardiovascular complications [14]. HDL exerts multiple atheroprotective functions, among them antioxidant activity, mainly performed by paraoxonase (PON-1), by hydrolysis of phospholipids and cholesterol ester hydroperoxides

[15]. Patients with ESRD, shows PON-1 reduced activity [16].

By the fact that patients maintained on HD have been exposed to many hete- 
rogeneous factors that result in quantitative and qualitative lipid abnormalities, the aim of this study was to investigate possible changes in lipids and lipoprotein parameters, such as paraoxonase activity, in vitro incorporation of phospholipids by enzymes associated with HDL, and cardiovascular risk indices on patients undergoing low-flow polysulfone hemodialysis.

\section{Materials and Methods}

\subsection{Subjects}

A cross-sectional study was conducted with 50 ESRD male patients, selected by convenience, undergoing HD at Ana Neri Hospital in Salvador, Brazil. All individuals were on $\mathrm{HD}$ for at least 3 months, into a protocol of three sessions of 3 4 hours per week, with a synthetic dialyzing membrane (polysulfone) of lowflow (Polypure ${ }^{\oplus}$, Germane), basic dialyzing solution (bicarbonate) and heparin unfractionated $\left(\mathrm{Hemofol}^{\circledR}\right)$. The origins of ESRD in those patients were: hypertension ( $n=9$ ), diabetic nephropathy $(n=7)$, HIV nephropathy $(n=1)$, chronic pyelonephritis $(n=1)$, polycystic kidney disease $(n=1)$ and unknown $(n=30)$. Patient's characteristics are shown in Table 1 . The study participants were stratified by age groups as follows: $30-39(\mathrm{n}=10), 40-49(\mathrm{n}=14), 50-59(\mathrm{n}=11)$ and $>60$ years $(n=15)$, according to the V Brazilian Guidelines of Dyslipidemia and Atherosclerosis Prevention criteria and the ESC/EAS Guidelines for the management of dyslipidemias [17] [32]. The study was approved by the research ethics committee from Federal University of Bahia, Brazil.

\subsection{Laboratory Methods}

Laboratory tests were performed on serum samples taken before and after the dialysis session. Concentrations of total cholesterol (TC), LDL-C, HDL-C, triglycerides (TG), total protein and albumin were determined by enzymatic methods (endpoint and kinetic reactions). Determinations of LDL-C were performed by homogeneous direct method (LDL-C direct BioSystems ${ }^{\oplus}$, Spain). Those tests were performed with two types of equipment: a semi-automated StarDust MC15 (Diasys, Germany) and an automated LabMax 240 Clinical Chemistry Analyzer (LABTEST, Brazil). The concentrations of apo-AI and apo $B$ were determined by immunonephelometry through a full automated analyzer, IMMAGE ${ }^{\bullet}$ (Beckman Coulter, USA).

Table 1. ESRD patient's features: age, BMI and hemodialysis treatment duration.

\begin{tabular}{cc}
\hline Feature & HD Patients $(\mathrm{n}=50)$ \\
\hline Age (years) & $57(32-72)$ \\
BMI $\left(\mathrm{Kg} / \mathrm{m}^{2}\right)$ & $23.4 \pm 3.4$ \\
Duration of Hemodialysis treatment (months) & $32.2 \pm 20$ \\
\hline
\end{tabular}

HD: hemodialysis; n: number; BMI: body mass index. Data is shown as mean \pm sd and median (range) for age. 


\subsection{Incorporation of Phospholipid into HDL}

The incorporation of phospholipids was determined by scintillation-counting of carbon- ${ }^{14}$ labeled-phospholipids $\left({ }^{14} \mathrm{C}-\mathrm{PL}\right)$ on $\mathrm{HDL}$ recovered fraction. The PL-incorporation method was developed from exogenous substrate method (STOKKE NORUM \& 1971; CHANNON, 1990). For each sample, 1.0 (one) microliter of ${ }^{14} \mathrm{C}$-PL $(0.4 \mu \mathrm{Ci} / \mathrm{mL})$ were added to 500 microliters of serum, homogenized by vortexing, and immediately placed into an ice bath $\left(0^{\circ} \mathrm{C}-4^{\circ} \mathrm{C}\right)$ for one hour, to establish a balance between endogenous (PL) and added ${ }^{14} \mathrm{C}-\mathrm{PL}$. After that time, samples were incubated for one hour at $37^{\circ} \mathrm{C}$ under constant agitation. Afterwards samples were cooled in an ice bath to halt reaction. So 250 microliters of labeled serum were separated to background reading, and another 250 microliters of labeled samples, were added to 250 microliters of precipitating reagent previously prepared with $0.2 \%$ dextran-sulfate and $3.0 \mathrm{Molar} \mathrm{MgCl}_{2}$, v/v to precipitate lipoproteins containing apoB. Subsequently, samples were centrifuged under refrigeration for 10 minutes at $3000 \mathrm{rpm}$ and supernatant containing HDL was separated to beta counting. The Hidex Chamaleon, a liquid scintillation multilabel detection platform (Turku, Finland) was used to counting detection. To evaluate repeatability and avoid light scattered interferences, samples were shared into five aliquots and pipetted into interspersed 96 wells ELISA plates. In each well were added aliquots of serum and scintillation solution, Ultima Gold (High flash-point LSC-cocktail for aqueous and non-aqueous samples -PerkinElmer, Inc., Waltham, USA), 50 and 250 microliters, respectively. HDL PL-incorporation was expressed as percentage of ${ }^{14} \mathrm{C}$-PL/counts-per-minute/hour.

\subsection{Paraoxonase (PON-1) Activity}

The PON-1 activity was measured according to Senti et al. [18]. $140 \mu \mathrm{L}$ of $0.1 \mathrm{M}$ Tris- $\mathrm{HCl}, \mathrm{pH} 8.5$, containing $\mathrm{CaCl}_{2}, 2 \mathrm{mmoL} / \mathrm{L}$, and paraoxon, $1.1 \mathrm{mmoL} / \mathrm{L}$, (Sigma Chemical Co.) and $7 \mu \mathrm{L}$ of serum were used. Samples were distributed in duplicate into a 96 well plate. Readings were done at $405 \mathrm{~nm}$ and $37^{\circ} \mathrm{C}$, using a Microplate Reader (Benchmark, Bio-Rad). For activity calculation, six readings were taken at intervals of one minute each, and results were obtained by multiplying average variation of absorbance factor.

\subsection{Bioindices}

The following lipid parameters were calculated: non-HDL-C (TC minus HDL-C), TG/HDL-C, apoB/apo-AI, TC/HDL-C, LDL-C/HDL-C, HDL-C/apo-AI, LDL-C/apoB, non-HDL-C/HDL-C and atherogenic index of plasma (AIP) $=\log$ (TG/HDL-C). As TG/HDL-C did not return a normal distribution for all subgroups, the log (TG/HDL-C) was used to confirm the finds. To AIP use, patients were classified according to three risk categories conventionally used, such as: $<0.11$ (low), 0.11 to 0.21 (intermediate) and $>0.21$ (high) [19].

\subsection{Statistical Analysis}

A descriptive analysis was performed to obtain summary measures, and normality 
test (Pearson Omnibus D'Agostotino) was used to access data distribution. For data with normal distribution, parametric tests were used, but if the data didn't attain normal distribution, non-parametric tests were used. To inferential analyses, data were considered significant when $\mathrm{p}<0.05$ for a confidence interval of 95\%. Preceding any statistical analysis, a Grubb's test was performed to outlier detection.

The Pearson's linear correlation coefficient was applied to calculate the correlation between two different parameters in the same group when data showed less dispersion around the line (homoscedasticity), and for those that showed heterocedasticity, Spearman's linear correlation coefficient was used. Data analyses were conducted at Graph Pad Prism 5.0 (Graph Pad Software, Inc., CA, USA).

\section{Results}

Our data shows significant increases on TC, HDL-C and non-HDL-C level at all age groups after HD. No significant differences were observed on TG levels when compared to pre- and post-HD (Table 2).

Apo-AI was increased after HD at age groups $30-39$ (p < 0.05), $40-49$ (p < $0.05)$ and $50-59$ years $(\mathrm{p}<0.01)$. Apo B was also increased at $40-49(\mathrm{p}<0.01)$, $50-59(\mathrm{p}<0.001)$ and $>60$ years $(\mathrm{p}<0.05)$, after HD. However, apo B/apo-AI ratio shows no significant difference among the tested groups. TG/HDL-C was reduced at age groups 30 - 39 and $40-49$ years ( $\mathrm{p}<0.05)$, when compared preand post-HD. Similar results were obtained for AIP. The LDL-C/apoB ratio increases at age groups $>60$ years $(p<0.05)$. The cholesterol quantity per HDL particle, estimated by HDL-C/apo-AI index, was increased at age groups $40-49$ $(\mathrm{p}<0.05)$ and $>60$ years $(\mathrm{p}<0.01)$. The reduction of non-HDL-C/HDL-C ratio was also observed at age groups $40-49$ and $>60$ years $(\mathrm{p}<0.05)$ (Table 3$)$.

There was a negative linear correlation between \% incorporation of ${ }^{14} \mathrm{C}-\mathrm{PL}$ and non-HDL-C/HDL-C at age group $30-39$ years (pre-, $r=-0.90, p=0.002$, and post-HD, $\mathrm{r}=-0.78, \mathrm{p}=0.022$, Pearson) and a positive correlation between PON-1 and $\%$ incorporation of ${ }^{14} \mathrm{C}-\mathrm{PL}$ at age group $>60$ years (pre-HD, $\mathrm{r}=0.63$, $\mathrm{p}=0.029$, post-HD, $\mathrm{r}=0.65, \mathrm{p}=0.022$ ). A positive correlation between $\mathrm{PON}-1$ and LDL-C/apoB was also observed at age group $>60$ years (pre-, $\mathrm{r}=0.62, \mathrm{p}=$ 0.032 , and post-HD, $\mathrm{r}=0.75, \mathrm{p}=0.003$ ) (Table 4).

Figure 1 shows the paraoxonase activity among different analyzed age groups. Only at age group $50-59$ years Pre- $(59 \pm 30)$ and Post-HD $(73 \pm 38)$, paraoxonase activity increases at post-HD $(\mathrm{p}<0.05)$. At the other age groups no differences were observed. Was observed a significant reduction of $\%$ phospholipid incorporation in post-HD $(\mathrm{p}<0.05)$ at age group $>60$ years, Pre- $(12 \pm 3)$ and post-HD $(10 \pm 3)$. Values of PON-1 activity and PL incorporation are shown as mean \pm standard deviation (Figure 1, Figure 2).

\section{Discussion}

PON-1 activity has been cited as the major antioxidant component of HDL [10], and the loss of its reductive capacity has been noticed on $\mathrm{HD}$ patients as a 
Table 2. Serum lipoprotein cholesterol, triglycerides, calculated estimates (LDL-C and Non-HDL-C) and proteins concentration from ESRD patient age group's at pre and post hemodialysis.

\begin{tabular}{ccccccccc}
\hline \multirow{2}{*}{ Age group } & \multicolumn{2}{c}{$30-39$ years } & \multicolumn{2}{c}{$40-49$ years } & \multicolumn{2}{c}{50 - 59 years } & \multicolumn{2}{c}{$>$ years } \\
\cline { 2 - 8 } & Pre-HD & Post-HD & Pre-HD & Post-HD & Pre-HD & Post-HD & Pre-HD & Post-HD \\
\hline TC (mg/dL) & $188 \pm 42^{*}$ & $209 \pm 56$ & $156 \pm 34^{* * *}$ & $190 \pm 40$ & $152 \pm 30^{* * *}$ & $176 \pm 37$ & $161 \pm 26^{* *}$ & $185 \pm 41$ \\
TG (mg/dL) & $274 \pm 222$ & $236 \pm 243$ & $172 \pm 98$ & $158 \pm 94$ & $170 \pm 85$ & $214 \pm 126$ & $148 \pm 94$ & $149 \pm 112$ \\
VLDL-C (mg/dL) & $44 \pm 25$ & $34 \pm 15$ & $36 \pm 19$ & $34 \pm 18$ & $34 \pm 14$ & $43 \pm 23$ & $31 \pm 18$ & $32 \pm 22$ \\
LDL-C (mg/dL) & $72 \pm 26$ & $88 \pm 27$ & $68 \pm 27$ & $74 \pm 39$ & $78 \pm 28$ & $85 \pm 28$ & $68 \pm 17^{* *}$ & $88 \pm 26$ \\
HDL-C (mg/dL) & $34 \pm 14^{* *}$ & $41 \pm 14$ & $30 \pm 11^{* * *}$ & $42 \pm 17$ & $37 \pm 11^{*}$ & $43 \pm 14$ & $34 \pm 12^{* * *}$ & $45 \pm 16$ \\
Non-HDL-C (mg/dL) & $156 \pm 49^{*}$ & $179 \pm 64$ & $126 \pm 41^{* *}$ & $149 \pm 48$ & $111 \pm 17^{* *}$ & $130 \pm 30$ & $125 \pm 33^{*}$ & $138 \pm 47$ \\
Total protein (g/dL) & $7.67 \pm 0.7^{* *}$ & $8.7 \pm 1.5$ & $7.03 \pm 0.5^{* * *}$ & $8.72 \pm 1.8$ & $8.38 \pm 1.9$ & $9.05 \pm 1.3$ & $7.28 \pm 0.3^{* *}$ & $8.2 \pm 1$ \\
Albumin (g/dL) & $4.44 \pm 0.38^{*}$ & $5.01 \pm 0.95$ & $4.28 \pm 0.64^{* * *}$ & $5.3 \pm 1.26$ & $4 \pm 0.57^{*}$ & $4.5 \pm 0.56$ & $4.1 \pm 0.35^{* * *}$ & $4.4 \pm 0.49$ \\
\hline
\end{tabular}

$\mathrm{TC}(\mathrm{mg} / \mathrm{dL})=$ Total Cholesterol; TG $(\mathrm{mg} / \mathrm{dL})=$ Triglycerides; VLDL-C $(\mathrm{mg} / \mathrm{dL})=$ Very Low Density Lipoprotein Cholesterol; LDL-C $(\mathrm{mg} / \mathrm{dL})=$ Low Density Lipoprotein Cholesterol; HDL-C $(\mathrm{mg} / \mathrm{dL})=$ High Density Lipoprotein Cholesterol; Non-HDL-C $(\mathrm{mg} / \mathrm{dL})=$ TC-HDL-C. Data are show as mean \pm sd values. Pre-HD compared Post-HD, ${ }^{*} \mathrm{p}<0.05 ;{ }^{* *} \mathrm{p}<0.01 ;{ }^{* *} \mathrm{p}<0.001$.

Table 3. Apolipoproteins and laboratory calculated indices from ESRD patient age groups at pre and post hemodialysis.

\begin{tabular}{ccccccccc}
\hline & \multicolumn{2}{c}{$30-39$ years } & \multicolumn{2}{c}{$40-49$ years } & \multicolumn{2}{c}{$50-59$ years } & \multicolumn{2}{c}{$>00$ years } \\
\hline & Pre-HD & Post-HD & Pre-HD & Post-HD & Pre-HD & Post-HD & Pre-HD & Post-HD \\
\hline Apo-AI (mg/dL) & $146.4 \pm 33.2^{*}$ & $165.4 \pm 35.4$ & $141.5 \pm 47^{*}$ & $161 \pm 45.7$ & $112.5 \pm 27.3^{* *}$ & $133.1 \pm 29.7$ & $151.2 \pm 32.7$ & $169.2 \pm 47.4$ \\
Apo B (mg/dL) & $97.6 \pm 24$ & $107.3 \pm 32.6$ & $78.9 \pm 32.5^{* *}$ & $91.8 \pm 39.5$ & $76 \pm 20.3^{* * *}$ & $89.6 \pm 23.9$ & $85.6 \pm 24.7^{*}$ & $93.8 \pm 26.7$ \\
Apo B/Apo-AI & $0.7 \pm 0.2$ & $0.7 \pm 0.2$ & $0.6 \pm 0.2$ & $0.6 \pm 0.3$ & $0.7 \pm 0.2$ & $0.7 \pm 0.3$ & $0.6 \pm 0.3$ & $0.6 \pm 0.3$ \\
TC/HDL-C & $6.4 \pm 2.9^{* *}$ & $5.7 \pm 2.9$ & $5.6 \pm 2.3^{* *}$ & $4.9 \pm 2.1$ & $4.5 \pm 1.8$ & $4.5 \pm 1.9$ & $5.4 \pm 3.5^{* *}$ & $4.6 \pm 2.6$ \\
LDL-C/HDL-C & $2.3 \pm 1.1$ & $2.3 \pm 0.8$ & $2.5 \pm 1.3$ & $2.2 \pm 1.7$ & $2.4 \pm 1.3$ & $2.2 \pm 1$ & $2.2 \pm 1,1$ & $2.2 \pm 1$ \\
TG/HDL-C & $11.3 \pm 14.3^{*}$ & $8 \pm 11.9$ & $6.8 \pm 5.4^{*}$ & $4.9 \pm 3.9$ & $5.3 \pm 3.7$ & $5.8 \pm 4.3$ & $6 \pm 8.4$ & $4.2 \pm 5.3$ \\
AIP & $0.5 \pm 0.45^{*}$ & $0.26 \pm 0.45$ & $0.36 \pm 0.37^{*}$ & $0.16 \pm 0.39$ & $0.35 \pm 0.25$ & $0.32 \pm 0.34$ & $0.22 \pm 0.41$ & $0.08 \pm 0.38$ \\
HDL-C/Apo-AI & $0.23 \pm 0.06$ & $0.26 \pm 0.07$ & $0.25 \pm 0.1^{*}$ & $0.32 \pm 0.2$ & $0.31 \pm 0.14$ & $0.3 \pm 0.09$ & $0.24 \pm 0.07^{* *}$ & $0.28 \pm 0.07$ \\
LDL-C/Apo B & $0.78 \pm 0.3$ & $0.93 \pm 0.3$ & $1 \pm 0.4$ & $1 \pm 0.4$ & $1.1 \pm 0.3$ & $1 \pm 0.2$ & $0.9 \pm 0.3^{*}$ & $1 \pm 0.3$ \\
Non-HDL-C/HDL-C & $4.8 \pm 2.3$ & $4.2 \pm 1.9$ & $4.6 \pm 2.3^{*}$ & $4.1 \pm 2$ & $3.4 \pm 0.8$ & $3.4 \pm 1.3$ & $3.5 \pm 1.7^{*}$ & $2.9 \pm 1.5$ \\
\hline
\end{tabular}

$\mathrm{TC}(\mathrm{mg} / \mathrm{dL})=$ Total Cholesterol; TG $(\mathrm{mg} / \mathrm{dL})=$ Triglycerides; VLDL-C $(\mathrm{mg} / \mathrm{dL})=$ Very Low Density Lipoprotein Cholesterol; LDL-C $(\mathrm{mg} / \mathrm{dL})=$ Low Density Lipoprotein Cholesterol; HDL-C $(\mathrm{mg} / \mathrm{dL})=$ High Density Lipoprotein Cholesterol; Non-HDL-C $(\mathrm{mg} / \mathrm{dL})=\mathrm{TC}-\mathrm{HDL}-\mathrm{C}$. Data are show as mean \pm sd values. Pre-HD compared Post-HD, ${ }^{*} \mathrm{p}<0.05 ;{ }^{* *} \mathrm{p}<0.01$; ${ }^{* *} \mathrm{p}<0.001$.

contributing factor for atherosclerosis development [20]. PON-1 is mentioned to be present at various steps of systemic oxidative stress, both in human and animal models [21]. We found a PON-1 activity significant increase, and our results were in agreement with the finds of Schiavon et al. [22]. They found a significant increase in PON-1 activity at pre- and post-HD, by conducting an experiment with 20 ESRD patients. Gugliucci et al. [3] in a similar study, also found a significant PON-1 increased activity at post-HD. However, they found a negative 
Table 4. ${ }^{14} \mathrm{C}-\mathrm{PL}$ and PON-1 linear correlation coefficient from ESRD patients age groups at pre and post hemodialysis.

\begin{tabular}{|c|c|c|c|c|c|c|c|c|}
\hline \multirow[t]{3}{*}{${ }^{14} \mathrm{C}-\mathrm{PL}$} & \multicolumn{8}{|c|}{ Non-HDL-C/HDL-C } \\
\hline & \multicolumn{2}{|c|}{$30-39$ years } & \multicolumn{2}{|c|}{$40-49$ years } & \multicolumn{2}{|c|}{$50-59$ years } & \multicolumn{2}{|c|}{$>60$ years } \\
\hline & Pre-HD & Post-HD & Pre-HD & Post-HD & Pre-HD & Post-HD & Pre-HD & Post-HD \\
\hline $\mathrm{r}$ & -0.90 & -0.78 & -0.07 & -0.35 & -0.57 & -0.03 & 0.01 & -0.04 \\
\hline $\mathrm{p}$ & $0.002^{* *}$ & $0.022^{*}$ & NS & NS & NS & NS & NS & NS \\
\hline \multirow[t]{3}{*}{ PON-1 } & \multicolumn{8}{|c|}{$\mathrm{PL}^{14} \mathrm{C}$} \\
\hline & \multicolumn{2}{|c|}{$30-39$ years } & \multicolumn{2}{|c|}{$40-49$ years } & \multicolumn{2}{|c|}{50 - 59 years } & \multicolumn{2}{|c|}{$>60$ years } \\
\hline & Pre-HD & Post-HD & Pre-HD & Post-HD & Pre-HD & Post-HD & Pre-HD & Post-HD \\
\hline $\mathrm{r}$ & -0.36 & 0.29 & 0.13 & -0.11 & 0.17 & 0.37 & 0.63 & 0.65 \\
\hline $\mathrm{p}$ & NS & NS & NS & NS & NS & NS & $0.029^{*}$ & $0.022^{*}$ \\
\hline
\end{tabular}

${ }^{14} \mathrm{C}-\mathrm{PL}=\%$ PL incorporation/mL/hours; PON-1 = Paraoxonase activity. Pre-HD compared Post-HD, ${ }^{*} \mathrm{p}<$ $0.05 ;{ }^{* *} \mathrm{p}<0.01 ;{ }^{* *} \mathrm{p}<0.001$.
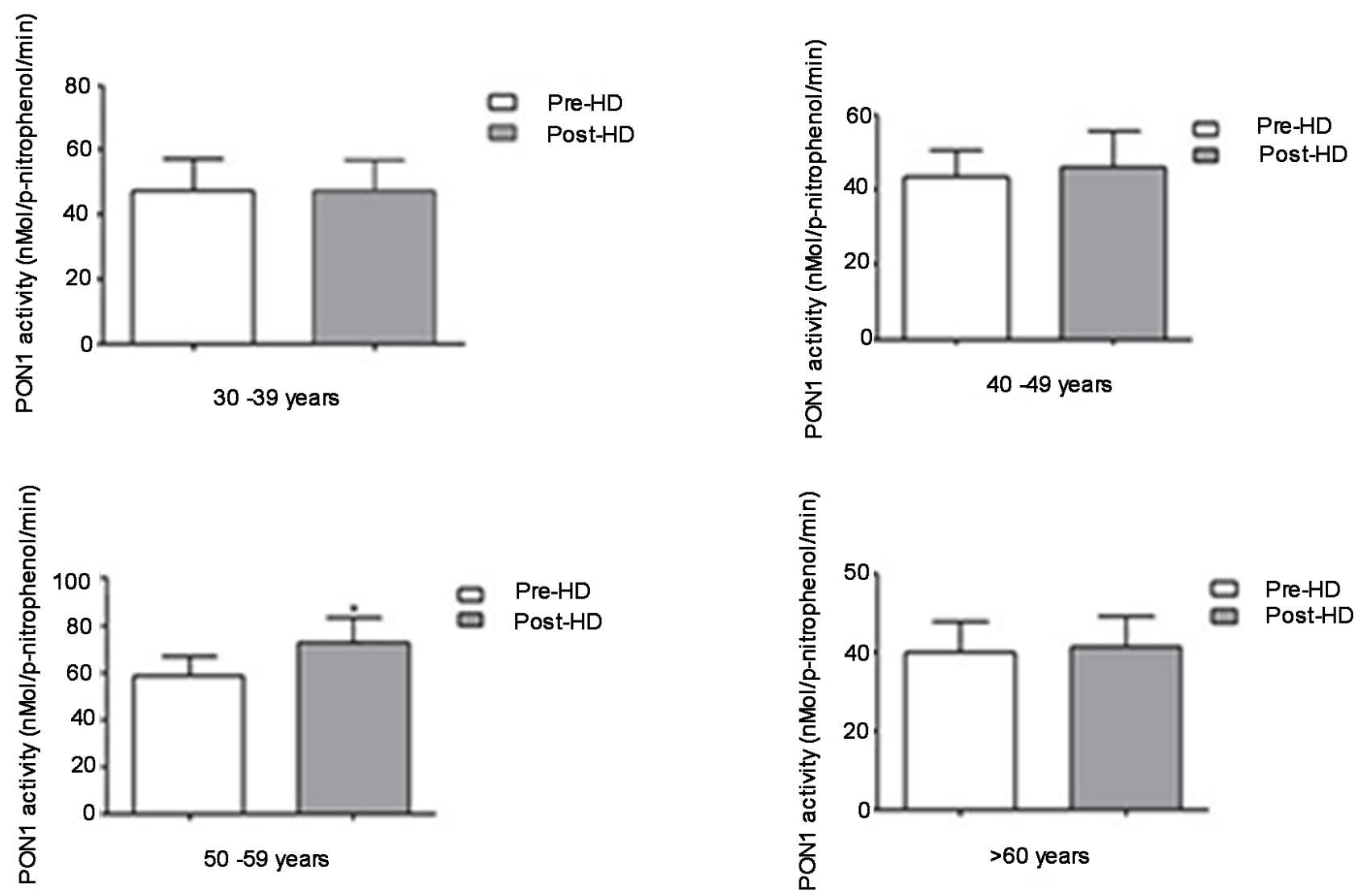

Figure 1. Paraoxonase activity determined by spectrophotometric method from samples of 50 patients undergoing hemodialysis; comparison between pre and post hemodialysis activities; paired $t$ test, Wilcoxon test post; significance at $\mathrm{p}<0.05,95 \%$ CI. Pre- vs Post-HD $\left(\mathrm{p}<0.05^{\star}\right)$, aged $50-59$ years.

correlation between PON-1 activity and serum concentrations of urea and creatinine. According to Gugliucci and colleagues, these results suggest another type of mechanism related to uremic toxins retention that possibly causes the 

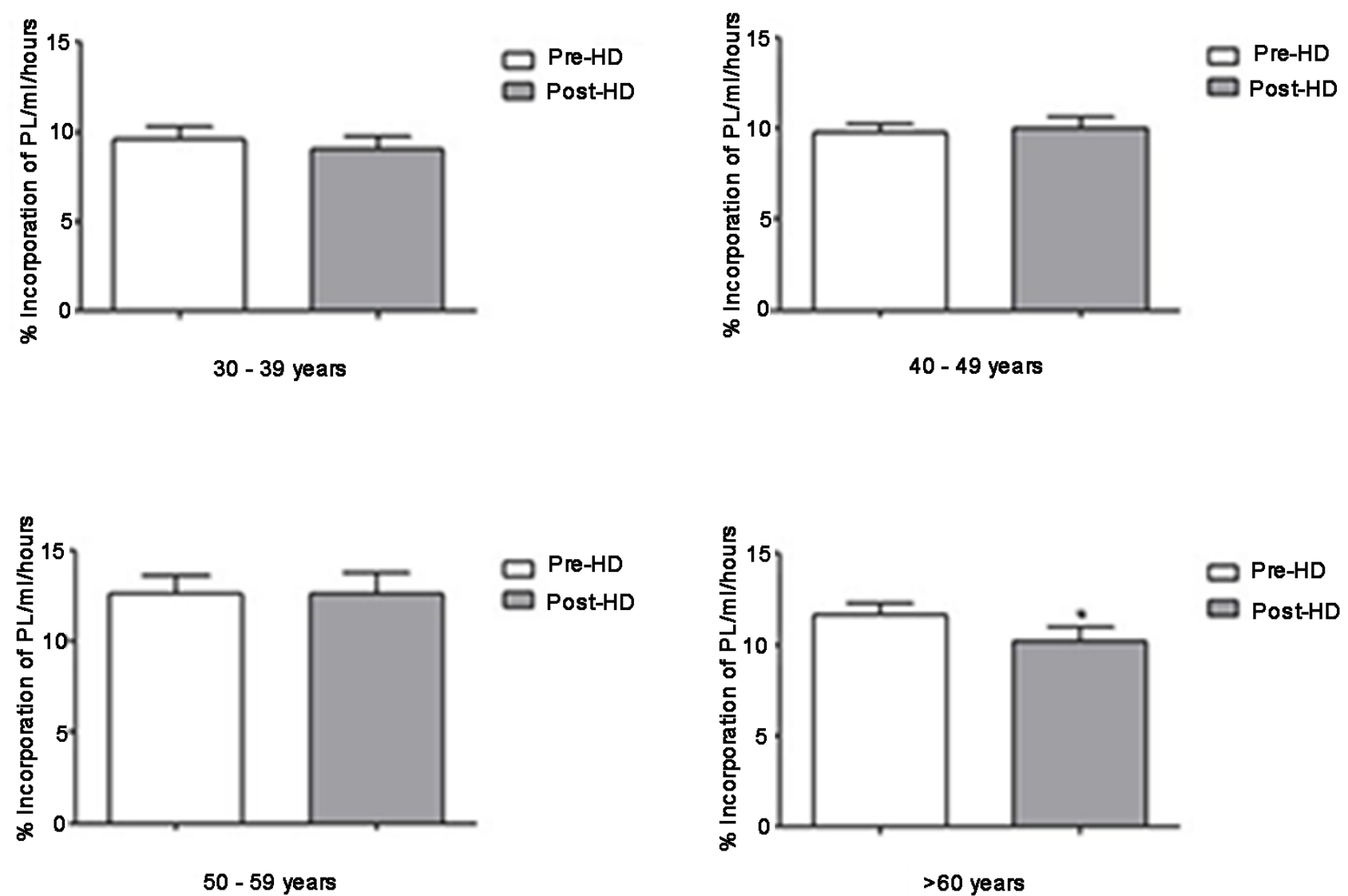

Figure 2. Incorporation of PL in HDL from different age groups by exogenous substrate, an in house method. Paired t-test, post Wilcoxon test; Significance for $\mathrm{p}<0.05,95 \%$ CI. Pre- vs Post-HD $\left(\mathrm{p}<0.05^{\star}\right)$, aged $>60$ years.

impairment of HDL's PON-1 antioxidant function [3]. Rajković et al. [20] also found a reduced PON-1 activity in patients with ESRD when replicating the in vitro experiments performed by Gugliucci et al. [3]. The obtained results show that high serum concentrations of urea, creatinine and uric acid had no impact on PON-1 activity. So, they found that molecules retained in the serum of hemodialyzed patients with relative molecular mass lower than $10.000 \mathrm{Da}$, did not have PON-1 activity inhibitory effect [3], but it is important to realize that PON-1 activity can be influenced by environmental factors and polymorphisms [23] [24] which could also explain the different results among studies.

The HDL atheroprotective efficiency depends on its structure and composition maintenance. PLTP is a transfer protein which has a central role in HDL metabolism due to its phospholipid transfer activity among lipoproteins [10]. In spite of that, some studies suggest that pro-inflammatory properties of PLTP may be associated with pro-atherosclerotic events [25] [26]. PON-1 and PLTP are HDL particle's constitutive enzymes/transfer proteins linked to apo-AI [3]. In the present study, we found a positive linear correlation between ${ }^{14} \mathrm{C}-\mathrm{PL}$ incorporation and PON-1 activity at patients $>60$ years, suggesting that both paraoxonase activity and HDL phospholipid transfer protein increases proportionally. Schlitt et al. [1], studying patients undergoing HD, found a positive correlation 
between PLTP activity and HDL-C, and Cheung et al. [27] [28] observed a positive correlation between PLTP and apo-AI. Our results show a significant reduction of ${ }^{14} \mathrm{C}-\mathrm{PL}$ incorporation at post-HD on patients $>60$ years, indicating a PLTP reduced activity. On the other hand, Pahl et al. [29] found no significant difference between PLTP activity and its plasmatic mass on serum of patients with ESRD when compared to the control group. According to this author, although systemic inflammation predominates in patients maintained on HD, such findings exclude the relationship between PLTP and inflammatory response on ESRD.

Several studies have reported that apolipoproteins are effective atherogenic markers. Apo-AI is said to be antiatherogenic and apo B as an atherogenic marker, apo B/apo-AI ratio reflects the balance between potentially atherogenic cholesterol-rich apo B-containing particles and antiatherogenicapo-AI rich particles, which is proposed as an integrated measurement of cardiac risk related to lipoprotein profile [30] [31].

In the present study, we found a significant increase in apo-AI and apoB serum's concentration at post-HD. However, we didn't find apoB/apo-AI ratio significant differences among all age groups. Although our study demonstrates that low-flow polysulfone HD elevates serum levels of apo-AI and apo B, the increase does not appear to be relevant, because when we calculate the apoB/apo-AI ratio it remained constant.

The European Cardiology Society clinical guide and the European Atherosclerosis Society recommends non-HDL-C as the best estimate of cardiovascular risk, compared to LDL-C, particularly on hypertriglyceridemic patients with ES-RD [32].

Furthermore, although apo B can be directly measured, the calculation of non-HDL-C is more practical, reliable and lower cost, and has been accepted as an apoB surrogate marker in clinical practice [33]. In spite of that, the calc of lipid ratios on hypertriglyceridemia, as non-HDL-C/HDL-C ratio should be a better cardiovascular risk estimate than the isolated analysis of non-HDL-C to predict the development of CHD in patients with type 2 diabetes [34]. In another observational study trying to find the best lipid parameter for prediction of CAD risk in type 2 diabetes, they show that non-HDL-C/HDL-C ratio was the best CAD risk estimate when compared to LDL-C, HDL-C, non-HDL-C [35]. In our study we found a significant increase of serum non-HDL-C and HDL-C concentrations on all age groups at post-HD. The non-HDL-C/HDL-C index shows significant decrease in age groups $40-49$ and $>60$ years at post-HD. Recently Kimak et al. [36] demonstrated a non-HDL-C/HDL-C ratio reduction in patients on HD, when compared to the control group.

At our correlation analysis, a negative linear correlation was obtained between $\mathrm{PL}^{14} \mathrm{C}$ incorporation and non-HDL-C/HDL-C ratio on age group $30-39$ years at pre and post-HD. So we found that the higher the PLTP activity, the higher the concentration of HDL-C was at post-HD. One in vitro study demonstrates the involvement of PLTP on HDL remodeling after incubation of homogeneous and 
spherical HDL populations containing apo-AI, cholesterol esters and triglycerides with PLTP. In that same study, the larger HDL particle's diameter formation was seen only after $3 \mathrm{~h}$ of experiment [37]. These results were confirmed by Van Haperen et al. [38]. After developing a murine model of transgenic mice (over expressing human PLTP), they realized a 2 to 3 times increase of serum pre- $\beta$-HDL formation compared to wild animals. In contrast, the HDL-C plasma levels of transgenic mice were reduced by $20 \%-30 \%$ when compared to the wild ones, and studies with PLTP knockout mice shows that enzyme activity deficiency causes significant HDL-C serum reduction [39] [40]. So far, evidence has shown that changes in serum levels of PLTP are directly related not only to HDL remodeling, but also to changes in HDL-C concentration.

Following metabolic disturbance of lipid and lipoprotein metabolism on HD patients, the uremic dyslipidemia is also characterized by the predominance of small density LDL (sdLDL) [41]. Studies have mentioned the association of sdLDL with an increased risk of myocardial infarction [42] [43]. In our study we didn't find significant differences in serum levels of triglyceride between preand post-HD, but we observed a significant increase of HDL-C at post-HD in all studied age groups, which led to a reduction of TG/HDL-C ratio on $30-39$ and 40 - 49 years age groups.

According to Da Luz et al. [44], TG/HDL-C ratio classifies LDL size into two different phenotypes: if above 3.8, there's a predominance of sdLDL (79\% phenotype B) and if under that, there's a phenotype A predominance (81\%) [45]. In our study, despite the reduction of TG/HDL-C ratio among some post-HD age groups, the pre- and post-HD average analysis showed that was no change in LDL phenotype estimate (TG/HDL-C). Likewise, when we used the classification proposed by Tani et al. [46], in which the results under 1.2 for LDL-C/apo B ratio (cholesterol concentration per LDL particle) indicate the presence of sdLDL. In addition, the LDL phenotype was different at age group $>60$ years from pre to post-HD. Although significant differences were observed between pre- and postHD for age group $>60$ years, the other evaluated age groups, by LDL-C/apoB ratio, did not show LDL phenotype changes. The Atherogenic Index of Plasma (AIP) has been cited recently as a risk marker for atherogenic disease since it indirectly indicates sdLDL in HD patients [19] [47] [48]. Our study showed a significant reduction of AIP at age groups 30 - 39 and 40 - 49 years. In the latter, it is important to point out that according to classification proposed by Holmes et al. [49], was a change from high (pre) to low risk (post-HD). On the other hand, Cabarkapa et al. [19] found a significant increase in AIP for HD patients when compared to CKD under conservative treatment and health individuals. The use of CT/HDL-C and LDL-C/HDL-C indexes is more reliable for the assessing of CVD risk than a lipid profile comprised by isolated parameters [50]. There was a reduction in TC/HDL-C ratio with a significant difference in all age groups at post-HD. Interestingly, at age groups $40-49$ and $>60$ years, patients changed from high to low risk category. According to Castelli et al. [51] male patients 
with TC/HDL-C index values greater than 5.1 should be considered in a high coronary risk classification. Some authors have questioned the influence of dialysate buffer on serum levels of HDL-C. Jung et al. [8] found an increase in serum HDL-C of patients on HD using bicarbonate-dialysate buffer when compared with acetate group, which results were confirmed in a similar study [9]. Based on those finds, the authors justified the improvement of "atherogenic index" (TC/HDL-C) on patients undergoing HD (bicarbonate) compared to those on HD (acetate). Recent data showed that TC/HDL-C is increased in CKD patients held on HD compared to a healthy population [36].

The plasmatic HDL is composed of heterogenous particle size lipoprotein populations which differ by their structures, compositions and biological functions. HDL heterogeneity results in different apolipoprotein and particle lipid content [52]. HDL-C/apo-AI ratio was increased at post-HD age groups $40-49$ and $>60$ years. These findings lead to an improvement of cholesterol load in HDL that may suggest particle size increase after HD [53]. Fernandez et al. [54] showed that HDL-C concentration was directly correlated to HDL diameter increase. According to Vekic et al. [55] larger lipoprotein diameter subclasses (HDL2a and HDL2b) are negatively correlated with CVD. By contrast, smaller ones (HDL3a, HDL3b and HDL3c) are positively correlated.

About the study limitations, we could not show patients characteristics and some nutritional status in detail. Data such as CRP, serum total protein, serum albumin, and dialysis efficiency such as $\mathrm{Kt} / \mathrm{V}$ (a marker of dialysis adequacy), ultrafiltration volume, dry weight (DW), and the ratio of ultrafiltration volume to DW during the sessions, by the study time, were unreachable from the medical records.

In conclusion, our study demonstrates that lipoprotein metabolism and laboratory surrogate biomarkers ratios of cardiac risk were altered during HD with low-flow polysulfone dialyzing-membrane, bicarbonate and unfractionated-heparin. The hemodialysis seems to influence the HDL remodeling by altering the ability to incorporate phospholipids, and decreasing the PON-1 activity. As we now know that uremic dyslipidemia behave differently from the common ones, new biomarkers to evaluate HDL remodeling should be used to evaluate patients maintained on hemodialysis. Other studies should be conducted to overcome our limitations.

\section{Acknowledgements}

The study was supported by grants from Fundação de Amparo a Pesquisa do Estado da Bahia-Bahia (FAPESB)/CNPq/ MS/SESAB_PPSUS. Franciane Santos Marques was a recipient of a fellowship from CPQGM-FIOCRUZ, Bahia, Brazil.

\section{Conflict of Interest}

There is no conflict of interest. 


\section{References}

[1] Schlitt, A., Heine, G.H., Jiang, X.C., Messow, M., Blankenberg, S., Rupprecht, H.J., et al. (2007) Phospholipid Transfer Protein in Hemodialysis Patients. American Journal of Nephrology, 27, 138-143. https://doi.org/10.1159/000099943

[2] Shoji, T., Abe, T., Matsuo, H., Egusa, G., Yamasaki, Y., Kashihara, N., et al. (2011) Chronic Kidney Disease, Dyslipidemia, and Atherosclerosis. Journal of Atherosclerosis and Thrombosis, 19, 299-315. https://doi.org/10.5551/jat.10454

[3] Gugliucci, A., Mehlhaff, K., Kinugasa, E., Ogata, H., Hermo, R., Schulze, J., et al. (2007) Paraoxonase-1 Concentrations in End-Stage Renal Disease Patients Increase after Hemodialysis: Correlation with Low Molecular AGE Adduct Clearance. Clinica Chimica Acta, 377, 213-220. https://doi.org/10.1016/j.cca.2006.09.028

[4] Yamamoto, S. and Kon, V. (2009) Mechanisms for Increased Cardiovascular Disease in Chronic Kidney Dysfunction. Current Opinion in Nephrology and Hypertension, 18, 181-188. https://doi.org/10.1097/MNH.0b013e328327b360

[5] Mitwalli, A.H., Alam, A.A., Al Wakeel, J.S. and Isnani, A.C. (2011) Dyslipidemia in Dialysis Patients. Saudi Journal of Kidney Diseases and Transplantation, 22, 689-694.

[6] Chmielewski, M., Carrero, J.J., Nordfors, L., Lindholm, B. and Stenvinkel, P. (2008) Lipid Disorders in Chronic Kidney Disease: Reverse Epidemiology and Therapeutic Approach. Journal of Nephrology, 21, 635-644.

[7] Lacquaniti, A., Bolignano, D., Donato, V., Bono, C., Fazio, M.R. and Buemi, M. (2010) Alterations of Lipid Metabolism in Chronic Nephropathies: Mechanisms, Diagnosis and Treatment. Kidney \& Blood Pressure Research, 33, 100-110. https://doi.org/10.1159/000302712

[8] Jung, K., Scheifler, A., Schulze, B.D. and Scholz, M. (1995) Lower Serum High-Density Lipoprotein-Cholesterol Concentration in Patients Undergoing Maintenance Hemodialysis with Acetate than with Bicarbonate. American Journal of Kidney Diseases, 25, 584-588. https://doi.org/10.1016/0272-6386(95)90127-2

[9] Abo-Zenah, H., Sabry, A., Farouk, A., Abdelhalim, N., El-Sayed, K. and Sobh, M. (2007) The Impact of Haemodialysis-Associated Variables on Lipid Profile in Egyptian Haemodialysis Population. International Urology and Nephrology, 39, 609-618. https://doi.org/10.1007/s11255-006-9162-x

[10] Cacciagiu, L.D., Gonzalez, A.I., Gomez Rosso, L., Merono, T., De Marziani, G., Elbert, A., et al. (2012) HDL-Associated Enzymes and Proteins in Hemodialysis Patients. Clinical Biochemistry, 45, 243-248.

https://doi.org/10.1016/j.clinbiochem.2011.12.008

[11] Oka, T., Kujiraoka, T., Ito, M., Egashira, T., Takahashi, S., Nanjee, M.N., et al. (2000) Distribution of Phospholipid Transfer Protein in Human Plasma: Presence of Two Forms of Phospholipid Transfer Protein, One Catalytically Active and the Other Inactive. The Journal of Lipid Research, 41, 1651-1657.

[12] Masson, D., Deckert, V., Gautier, T., Klein, A., Desrumaux, C., Viglietta, C., et al. (2011) Worsening of Diet-Induced Atherosclerosis in a New Model of Transgenic Rabbit Expressing the Human Plasma Phospholipid Transfer Protein. Arteriosclerosis, Thrombosis, and Vascular Biology, 31, 766-774.

https://doi.org/10.1161/ATVBAHA.110.215756

[13] vanHaperen, R., van Tol, A., van Gent, T., Scheek, L., Visser, P., van der Kamp, A., et al. (2002) Increased Risk of Atherosclerosis by Elevated Plasma Levels of Phospholipid Transfer Protein. The Journal of Biological Chemistry, 277, 48938-48943. https://doi.org/10.1074/jbc.M209128200 
[14] Attia, N., Domingo, N., Lorec, A.M., Nakbi, A., Hammami, S., Ben Hamda, K., et al. (2009) Reverse Modulation of the HDL Anionic Peptide Factor and Phospholipid Transfer Protein Activity in Coronary Artery Disease and Type 2 Diabetes Mellitus. Clinical Biochemistry, 42, 845-851.

https://doi.org/10.1016/j.clinbiochem.2008.12.008

[15] Superko, H.R. (2009) Cardiovascular Event Risk: High-Density Lipoprotein and Paraoxonase. Journal of the American College of Cardiology, 54, 1246-1248. https://doi.org/10.1016/j.jacc.2009.07.006

[16] Gugliucci, A., Kinugasa, E., Kotani, K., Caccavello, R. and Kimura, S. (2011) Serum Paraoxonase 1 (PON1) Lactonase Activity Is Lower in End-Stage Renal Disease Patients than in Healthy Control Subjects and Increases after Hemodialysis. Clinical Chemistry and Laboratory Medicine, 49, 61-67. https://doi.org/10.1515/CCLM.2011.004

[17] Xavier, H.T., Izar, M.C., FariaNeto, J.R., Assad, M.H., Rocha, V.Z., Sposito, A.C., et al. (2013) V Brazilian Guideline for Dyslipidemia and Atherosclerosis Prevention: Department of Atherosclerosis of Brazilian Society of Cardiology. Arquivos Brasileiros de Cardiologia, 101, 22.

[18] Senti, M., Tomas, M., Fito, M., Weinbrenner, T., Covas, M.I., Sala, J., et al. (2003) Antioxidant Paraoxonase 1 Activity in the Metabolic Syndrome. The Journal of Clinical Endocrinology \& Metabolism, 88, 5422-5426. https://doi.org/10.1210/jc.2003-030648

[19] Cabarkapa, V., Djeric, M., Stosic, Z., Sakac, V., Lozanov-Crvenkovic, Z. and Vuckovic, B. (2012) Evaluation of Lipid Parameters and Bioindices in Patients with Different Stages of Chronic Renal Failure. Vojnosanitetski Pregled, 69, 961-966. https://doi.org/10.2298/VSP1211961C

[20] Rajkovic, M.G., Rumora, L., Juretic, D., Grubisic, T.Z., Flegar-Mestric, Z., Vrkic, N., et al. (2010) Effect of Non-Genetic Factors on Paraoxonase 1 Activity in Patients Undergoing Hemodialysis. Clinical Biochemistry, 43, 1375-1380. https://doi.org/10.1016/j.clinbiochem.2010.08.024

[21] Kennedy, D.J., Tang, W.H., Fan, Y., Wu, Y., Mann, S., Pepoy, M., et al. (2013) Diminished Antioxidant Activity of High-Density Lipoprotein-Associated Proteins in Chronic Kidney Disease. Journal of the American Heart Association, 2, e000104. https://doi.org/10.1161/JAHA.112.000104

[22] Schiavon, R., De Fanti, E., Giavarina, D., Biasioli, S., Cavalcanti, G. and Guidi, G. (1996) Serum Paraoxonase Activity Is Decreased in Uremic Patients. Clinica Chimica Acta, 247, 71-80. https://doi.org/10.1016/0009-8981(95)06221-1

[23] Camps, J., Garcia-Heredia, A., Rull, A., Alonso-Villaverde, C., Aragones, G., Beltran-Debon, R., et al. (2012) PPARs in Regulation of Paraoxonases: Control of Oxidative Stress and Inflammation Pathways. PPAR Research, 2012, Article ID: 616371. https://doi.org/10.1155/2012/616371

[24] Gugliucci, A., Kotani, K. and Kimura, S. (2012) Paraoxonase 1 in Chronic Kidney Failure. Journal of Lipids, 2012, Article ID: 726048. https://doi.org/10.1155/2012/726048

[25] Yan, D., Navab, M., Bruce, C., Fogelman, A.M. and Jiang, X.C. (2004) PLTP Deficiency Improves the Anti-Inflammatory Properties of HDL and Reduces the Ability of LDL to Induce Monocyte Chemotactic Activity. The Journal of Lipid Research, 45, 1852-1858. https://doi.org/10.1194/jlr.M400053-JLR200

[26] Schlitt, A., Liu, J., Yan, D., Mondragon-Escorpizo, M., Norin, A.J. and Jiang, X.C. (2005) Anti-Inflammatory Effects of Phospholipid Transfer Protein (PLTP) Deficiency in Mice. Biochimica et Biophysica Acta, 1733, 187-191. 
https://doi.org/10.1016/j.bbalip.2004.12.011

[27] Cheung, M.C., Wolfbauer, G., Brown, B.G. and Albers, J.J. (1999) Relationship between Plasma Phospholipid Transfer Protein Activity and HDL Subclasses among Patients with Low HDL and Cardiovascular Disease. Atherosclerosis, 142, 201-205. https://doi.org/10.1016/S0021-9150(98)00190-7

[28] Cheung, M.C., Brown, B.G., Marino Larsen, E.K., Frutkin, A.D., O'Brien, K.D. and Albers, J.J. (2006) Phospholipid Transfer Protein Activity Is Associated with Inflammatory Markers in Patients with Cardiovascular Disease. Biochimica et Biophysica Acta, 1762, 131-137. https://doi.org/10.1016/j.bbadis.2005.09.002

[29] Pahl, M.V., Ni, Z., Sepassi, L., Moradi, H. and Vaziri, N.D. (2009) Plasma Phospholipid Transfer Protein, Cholesteryl Ester Transfer Protein and Lecithin:Cholesterol Acyltransferase in End-Stage Renal Disease (ESRD). Nephrology Dialysis Transplantation, 24, 2541-2546. https://doi.org/10.1093/ndt/gfp120

[30] Huang, F., Yang, Z., Xu, B., Bi, Y., Xu, M., Xu, Y., et al. (2013) Both Serum Apolipoprotein B and the Apolipoprotein B/Apolipoprotein A-I Ratio Are Associated with Carotid Intima-Media Thickness. PLOS ONE, 8, e54628.

https://doi.org/10.1371/journal.pone.0054628

[31] Walldius, G., Jungner, I., Aastveit, A.H., Holme, I., Furberg, C.D. and Sniderman, A.D. (2004) The apoB/apoA-I Ratio Is Better than the Cholesterol Ratios to Estimate the Balance between Plasma Proatherogenic and Antiatherogenic Lipoproteins and to Predict Coronary Risk. Clinical Chemistry and Laboratory Medicine, 42, 1355-1363. https://doi.org/10.1515/CCLM.2004.254

[32] Catapano, A.L., Graham, I., De Backer, G., Wiklund, O., Chapman, M.J., Drexel, H., et al. (2016) ESC/EAS Guidelines for the Management of Dyslipidaemias the Task Force for the Management of Dyslipidaemias of the European Society of Cardiology (ESC) and European Atherosclerosis Society (EAS) - Developed with the Special Contribution of the European Association for Cardiovascular Prevention \& Rehabilitation (EACPR). European Heart Journal, 1-72. [In Press]

[33] Peters, A.L. (2008) Clinical Relevance of Non-HDL Cholesterol in Patients with Diabetes. Clinical Diabetes, 26, 3-7. https://doi.org/10.2337/diaclin.26.1.3

[34] Holman, R.R., Coleman, R.L., Shine, B.S. and Stevens, R.J. (2005) Non-HDL Cholesterol Is Less Informative than the Total-to-HDL Cholesterol Ratio in Predicting Cardiovascular Risk in Type 2 Diabetes. Diabetes Care, 28, 1796-1797. https://doi.org/10.2337/diacare.28.7.1796

[35] Eliasson, B., Cederholm, J., Eeg-Olofsson, K., Svensson, A.M., Zethelius, B. and Gudbjornsdottir, S. (2011) Clinical Usefulness of Different Lipid Measures for Prediction of Coronary Heart Disease in Type 2 Diabetes: A Report from the Swedish National Diabetes Register. Diabetes Care, 34, 2095-2100. https://doi.org/10.2337/dc11-0209

[36] Kimak, E., Halabis, M., Baranowicz-Gaszczyk, I., Solski, J. and Ksiazek, A. (2011) Association between Moderately Oxidized Low-Density Lipoprotein and High-Density Lipoprotein Particle Subclass Distribution in Hemodialyzed and Post-Renal Transplant Patients. Journal of Zhejiang University Science B, 12, 365-371. https://doi.org/10.1631/jzus.B1000348

[37] Settasatian, N., Duong, M., Curtiss, L.K., Ehnholm, C., Jauhiainen, M., Huuskonen, J., et al. (2001) The Mechanism of the Remodeling of High Density Lipoproteins by Phospholipid Transfer Protein. The Journal of Biological Chemistry, 276, 26898-26905. https://doi.org/10.1074/jbc.M010708200 
[38] van Haperen, R., van Tol, A., Vermeulen, P., Jauhiainen, M., van Gent, T., van den Berg, P., et al. (2000) Human Plasma Phospholipid Transfer Protein Increases the Antiatherogenic Potential of High Density Lipoproteins in Transgenic Mice. Arteriosclerosis, Thrombosis, and Vascular Biology, 20, 1082-1088. https://doi.org/10.1161/01.ATV.20.4.1082

[39] Yazdanyar, A., Yeang, C. and Jiang, X.-C. (2011) Role of Phospholipid Transfer Protein in High-Density Lipoprotein-Mediated Reverse Cholesterol Transport. Current Atherosclerosis Reports, 13, 242-248. https://doi.org/10.1007/s11883-011-0172-5

[40] Dullaart, R.P., van Tol, A. and Dallinga-Thie, G.M. (2013) Phospholipid Transfer Protein, an Emerging Cardiometabolic Risk Marker: Is It Time to Intervene? Atherosclerosis, 228, 38-41. https://doi.org/10.1016/j.atherosclerosis.2013.01.043

[41] Tsimihodimos, V., Mitrogianni, Z. and Elisaf, M. (2011) Dyslipidemia Associated with Chronic Kidney Disease. Open Cardiovascular Medicine Journal, 5, 41-48. https://doi.org/10.2174/1874192401105010041

[42] Tsunoda, F., Koba, S., Hirano, T., Ban, Y., Iso, Y., Suzuki, H., et al. (2004) Association between Small Dense Low-Density Lipoprotein and Postprandial Accumulation of Triglyceride-Rich Remnant-Like Particles in Normotriglyceridemic Patients with Myocardial Infarction. Circulation Journal, 68, 1165-1172. https://doi.org/10.1253/circj.68.1165

[43] Koba, S., Hirano, T., Murayama, S., Kotani, T., Tsunoda, F., Iso, Y., et al. (2003) Small Dense LDL Phenotype Is Associated with Postprandial Increases of Large VLDL and Remnant-Like Particles in Patients with Acute Myocardial Infarction. Atherosclerosis, 170, 131-140. https://doi.org/10.1016/S0021-9150(03)00245-4

[44] Da Luz, P.L., Favarato, D., Faria-Neto Junior, J.R., Lemos, P. and Chagas, A.C.P. (2008) High Ratio of Triglycerides to HDL-Cholesterol Predicts Extensive Coronary Disease. Clinics, 63, 427-432. https://doi.org/10.1590/S1807-59322008000400003

[45] Rizzo, M., Barbagallo, C.M., Severino, M., Polizzi, F., Onorato, F., Noto, D., et al. (2003) Low-Density-Lipoprotein Peak Particle Size in a Mediterranean Population. European Journal of Clinical Investigation, 33, 126-133. https://doi.org/10.1046/j.1365-2362.2003.01125.x

[46] Tani, S., Saito, Y., Anazawa, T., Kawamata, H., Furuya, S., Takahashi, H., et al. (2011) Low-Density Lipoprotein Cholesterol/Apolipoprotein B Ratio May Be a Useful Index That Differs in Statin-Treated Patients with and without Coronary Artery Disease: A Case Control Study. International Heart Journal, 52, 343-347. https://doi.org/10.1536/ihj.52.343

[47] Erdur, M.F., Tonbul, H.Z., Ozbiner, H., Ozcicek, A., Ozcicek, F., Akbas, E.M., et al. (2013) The Relationship between Atherogenic Index of Plasma and Epicardial Adipose Tissue in Hemodialysis and Peritoneal Dialysis Patients. Renal Failure, 35, 1193-1198. https://doi.org/10.3109/0886022X.2013.823826

[48] Yildiz, G., Duman, A., Aydin, H., Yilmaz, A., Hur, E., Magden, K., et al. (2013) Evaluation of Association between Atherogenic Index of Plasma and Intima-Media thickness of the Carotid Artery for Subclinic Atherosclerosis in Patients on Maintenance Hemodialysis. Hemodialysis International, 17, 397-405. https://doi.org/10.1111/hdi.12041

[49] Holmes, D.T., Frohlich, J. and Buhr, K.A. (2008) The Concept of Precision Extended to the Atherogenic Index of Plasma. Clinical Biochemistry, 41, 631-635. https://doi.org/10.1016/j.clinbiochem.2008.01.023 
[50] Yang, D., Liu, X. and Xiang, M. (2011) The Correlation between Lipids Ratio and Degree of Coronary Artery Stenosis. High Blood Pressure \& Cardiovascular Prevention, 18, 53-56. https://doi.org/10.2165/11593480-000000000-00000

[51] Castelli, W.P., Abbott, R.D. and McNamara, P.M. (1983) Summary Estimates of Cholesterol Used to Predict Coronary Heart Disease. Circulation, 67, 730-734.

https://doi.org/10.1161/01.CIR.67.4.730

[52] Camont, L., Chapman, M.J. and Kontush, A. (2011) Biological Activities of HDL Subpopulations and Their Relevance to Cardiovascular Disease. Trends in Molecular Medicine, 17, 594-603. https://doi.org/10.1016/j.molmed.2011.05.013

[53] Abbasi, A., Corpeleijn, E., Gansevoort, R.T., Gans, R.O., Hillege, H.L., Stolk, R.P., et al. (2013) Role of HDL Cholesterol and Estimates of HDL Particle Composition in Future Development of Type 2 Diabetes in the General Population: The PREVEND Study. The Journal of Clinical Endocrinology \& Metabolism, 98, E1352-E1359. https://doi.org/10.1210/jc.2013-1680

[54] Fernandez, M.L., Jones, J.J., Ackerman, D., Barona, J., Calle, M., Comperatore, M.V., et al. (2010) Low HDL Cholesterol Is Associated with Increased Atherogenic Lipoproteins and Insulin Resistance in Women Classified with Metabolic Syndrome. Nutrition Research and Practice, 4, 492-498. https://doi.org/10.4162/nrp.2010.4.6.492

[55] Vekic, J., Kotur-Stevuljevic, J., Jelic-Ivanovic, Z., Spasic, S., Spasojevic-Kalimanovska, V., Topic, A., et al. (2007) Association of Oxidative Stress and PON1 with LDL and HDL Particle Size in Middle-Aged Subjects. European Journal of Clinical Investigation, 37, 715-723. https://doi.org/10.1111/j.1365-2362.2007.01849.x

\section{Nonstandard Abbreviations}

Apo: Apolipoprotein

sdLDL: Small and dense LDL

TG: Triglycerides

TC: Total cholesterol

Pre-HD: Pre Hemodialysis

Post-HD: Post Hemodialysis

${ }^{14} \mathrm{C}-\mathrm{PL}$ : Phospholipid-14C labeled

PON-1: Paraoxonase 
Submit or recommend next manuscript to SCIRP and we will provide best service for you:

Accepting pre-submission inquiries through Email, Facebook, LinkedIn, Twitter, etc. A wide selection of journals (inclusive of 9 subjects, more than 200 journals)

Providing 24-hour high-quality service

User-friendly online submission system

Fair and swift peer-review system

Efficient typesetting and proofreading procedure

Display of the result of downloads and visits, as well as the number of cited articles Maximum dissemination of your research work

Submit your manuscript at: http://papersubmission.scirp.org/

Or contact jbpc@scirp.org 